\title{
Molecular Characterization of the 16S rRNA Gene of Helicobacter fennelliae Isolated from Stools and Blood Cultures from Paediatric Patients in South Africa
}

\author{
Heidi E. M. Smuts ${ }^{1}$ and Albert Joseph Lastovica ${ }^{2}$ \\ ${ }^{1}$ Division of Medical Virology/National Health Laboratory Service, Department of Clinical Laboratory Sciences, \\ University of Cape Town, Anzio Road, Observatory 7925, South Africa \\ ${ }^{2}$ Department of Biotechnology, University of the Western Cape, Modderdam Road, Bellville 7535, South Africa
}

Correspondence should be addressed to Heidi E. M. Smuts, heidi.smuts@uct.ac.za

Received 23 July 2010; Revised 27 September 2010; Accepted 4 October 2010

Academic Editor: Chiung-Yu Hung

Copyright (C 2011 H. E. M. Smuts and A. J. Lastovica. This is an open access article distributed under the Creative Commons Attribution License, which permits unrestricted use, distribution, and reproduction in any medium, provided the original work is properly cited.

\begin{abstract}
Forty strains of $H$. fennelliae collected from paediatric blood and stool samples over an 18 year period at a children's hospital in Cape Town, South Africa, were amplified by PCR of the $16 \mathrm{~S}$ rRNA. Two distinct genotypes of H. fennelliae were identified based on the phylogenetic analysis. This was confirmed by sequencing a portion of the beta subunit of the RNA polymerase (rpoB) gene. All isolates from South Africa clustered with a proposed novel Helicobacter strain (accession number AF237612) isolated in Australia, while three H. fennelliae type strains from the northern hemisphere, NCTC 11612, LMG 7546 and CCUG 18820 , formed a separate branch. A large (355bp) highly conserved intervening sequence (IVS) in the 16S rRNA was found in all isolates. Predicted secondary structures of the IVS from the 16S rRNA and 23S rRNA were characterised by a primary stem structure formed by base pairing of the $3^{\prime}$ and $5^{\prime}$ ends and internal loops and stems. This phylogenetic analysis is the largest undertaken of H. fennelliae. The South African $H$. fennelliae isolates are closely related to an Australian isolate previously reported to be a possible novel species of Helicobacter. This study suggests that the latter is strain of $H$. fennelliae.
\end{abstract}

\section{Introduction}

Since the discovery of Helicobacter pylori (H. pylori) by Warren and Marshall in 1983 [1], more than 30 non-pyloriHelicobacter species have been described $[2,3]$. To date, $H$. bizzozeronnii, $H$. canadensis, $H$. canis, $H$. cinaedi, $H$. fennelliae, $H$. felis, $H$. heilmannii, $H$. pullorum, H. rappini, $H$. salomonis, $H$. winghamensis, and $H$. westmeadii have been found in humans with gastritis, enteritis, and septicaemia [3-8]. H. fennelliae was first described in 1985 as a new Campylobacter species isolated from asymptomatic homosexual men with enteritis and proctitis [9]. This organism was subsequently reclassified as a Helicobacter species based on 23S rRNA hybridisation studies [10]. H. fennelliae is a fastidious organism and difficult to culture; thus, there are very few reports of the clinical relevance of the organism. In 2000, Tee et al. [11] described a novel species of Helicobacter isolated from the blood of a young aboriginal child with diarrhoea and vomiting which was most closely related to $H$. fennelliae. The authors proposed, this may be a new species of Helicobacter.

From 1977 to 1990, the routine microbiological laboratories at Red Cross War Memorial Children's and Groote Schuur Hospitals in Cape Town, South Africa used a variety of antibiotic-containing media plates and standard microaerophilic atmospheric growth conditions for the isolation of Campylobacter and other Epsilonproteobacteria. $H$. fennelliae and other fastidious $\mathrm{H}_{2}$-requiring and antibioticsensitive Epsilonproteobacteria were never isolated under these conditions [12]. With the introduction of the "Cape Town protocol", an isolation method that uses membrane filtration onto antibiotic-free plates and subsequent incubation in an $\mathrm{H}_{2}$-enriched microaerophilic atmosphere, $H$. fennelliae and other fastidious Epsilonproteobacteria were, and still are, 
routinely isolated from paediatric stool and blood cultures in Cape Town [12]. Over an 18-year period, since the introduction of this protocol in October 1990, H. fennelliae has been isolated from 5.6\% (347/6249) stool samples from children with diarrhoea [8]. In addition, $H$. fennelliae was isolated from 15/174 (8.6\%) paediatric blood culture samples negative for Campylobacter or other Helicobacter species. This is highly suggestive of the fact that $H$. fennelliae may be a significant pathogen and is probably considerably underreported due to inadequate isolation methods [12].

Phenotypic and biochemical tests are usually used to identify bacterial isolates in the clinical setting. However, there are limitations to these assays, and thus sequencing and the phylogenetic analysis of the 16S rRNA are often utilised to identify new isolates.

The access to a large number of $H$. fennelliae isolates from Cape Town provided the opportunity to look at the genetic diversity of these isolates and compare the data to that available in the GenBank database. The 16S rRNA and a portion of the RNA polymerase subunit B (rpoB) gene were analysed.

\section{Materials and Methods}

2.1. Bacterial Stains. Forty previously characterised strains of $H$. fennelliae collected from paediatric stool and blood samples over an 18-year period, from 1990-2008, were analysed in this study. Characterisation was performed using standard phenotypic and biochemical methods [12]. Clinical data is shown in Table 1 . The H. fennelliae reference strain, NCTC 11612, was also included.

2.2. DNA Extraction. DNA was extracted using either the CTAB methodology [13] or a boiling method. Briefly, a couple of microbeads maintained at $-80^{\circ} \mathrm{C}$ were removed and added to $100 \mu \mathrm{l}$ of distilled water. The beads were boiled for 5 minutes and the supernatant used in the PCR reaction.

2.3. PCR Amplification. The $16 \mathrm{~S}$ rRNA was amplified using primers designed by Marshal et al. [14]. Initially a portion of the rpoB gene was amplified with primers designed by Lim et al. [15]. To improve phylogenetic resolution, an additional antisense primer (5; TTGCATCATCATGCTCC) amplifying a larger region (704 bp) was designed, based on the sequence data of Kuhnert and Burnens [16]. Two microlitres of extracted DNA or boilate was added to a $50 \mu \mathrm{l}$ PCR mix consisting of $2 \mathrm{U}$ Super-therm polymerase, 1x PCR reaction buffer, $1.5 \mathrm{mM} \mathrm{MgCl}_{2}$ (JMR Holdings, Kent, UK), and $200 \mu \mathrm{M}$ of each dNTP (Roche Biochemicals, Mannheim, Germany). The cycling conditions were 1 cycle $95^{\circ} \mathrm{C} 2$ minutes, 40 cycles of $95^{\circ} \mathrm{C} 15 \mathrm{sec}, 52^{\circ} \mathrm{C} 25 \mathrm{sec}$, and $72^{\circ} \mathrm{C} 35 \mathrm{sec}$ followed by a final 7 -minute extension cycle at $72^{\circ} \mathrm{C}$. The PCR products were analysed by $2 \%$ agarose gel electrophoresis and visualised with UV irradiation after staining with ethidium bromide.

2.4. Sequencing and Phylogenetic Analysis. PCR products of the 16S rRNA and rpoB genes were purified (Qiagen,
Hilden, Germany) and sequenced directly using the BigDye Terminator ver1.1 commercial kit (Applied Biosystems, CA, USA). The nucleotide sequences were aligned with known sequences from GenBank using the CLUSTAL-X software [17]. A neighbour-joining phylogenetic tree was constructed using the Treecon software program (version 1,3b) with 500 bootstrap resamplings [18].

2.5. IVS Secondary Structure. The secondary structure of the $16 \mathrm{~S}$ rRNA intervening sequence (IVS) of $H$. fennelliae with the lowest free energy was predicted using mfold version $3.2[19,20]$. An IVS has also been found in the $23 \mathrm{~S}$ rRNA of $H$. fennelliae isolate CCUG 18820 (accession number AY596237) [21], and a comparison between the IVS of the $23 \mathrm{~S}$ rRNA and $16 \mathrm{~S}$ rRNA was made.

2.6. Accession Numbers. The accession numbers of the $16 \mathrm{~S}$ rRNA sequences of $H$. fennelliae from this study are GQ867137-GQ867176. The rpoB sequence accession numbers are GQ867083-GQ867136.

\section{Results}

3.1. PCR Detection. The $16 \mathrm{~S}$ rRNA of all 40 isolates of $H$. fennelliae were successfully amplified, yielding a 1340-bp product. This is larger than the other Helicobacter species due to the presence of IVS in $H$. fennelliae. A representative sample of 16S rRNA PCR products amplified from different Helicobacter clinical isolates is shown (Figure 1(a)). The rpoB gene was amplified from 32/40 (80\%) isolates, with some examples shown (Figure 1(b)).

3.2. Clinical Information. Clinical and demographic data are shown in Table 1. The mean age of the 40 children from whom $H$. fennelliae was isolated was 14 months (range: 148 months). The male: female ratio was similar, $1.0: 1.1$. The majority of the children presented with symptoms of diarrhoea $(31 / 40,77.5 \%)$. H. fennelliae was isolated from blood cultures in 5 cases; 2 children had pneumonia, 2 had diarrhoea, and there was a single case of meningococcaemia. The immunological status of these children was not known. Dual infection with other enteric organisms was found in 21 samples $(52.5 \%)$ of which the majority $(19 / 21,90 \%)$ were Campylobacter species, and in 2 samples Shigella and Giardia species were found. In the remaining 19 samples, $H$. fennelliae was the only organism cultured. The samples were not screened for viral enteric pathogens.

3.3. Phylogenetic Analysis. Sequence analysis confirmed the identification of $H$. fennelliae isolates. The $16 \mathrm{~S}$ rRNA phylogenetic tree was rooted with Campylobacter jejuni subsp. jejuni (accession number NC_002163) and showed two distinct branches of $H$. fennelliae. The isolates from South Africa all branched with an Australian Helicobacter strain (accession number AF237612), while those from Europe and USA formed a separate branch with a bootstrap value of 100\% (Figure 2(a)). This branching pattern was not present using the smaller rpoB PCR fragment (data not shown), 
Table 1: Clinical and demographic details of the H. fennelliae isolates from paediatric stool and blood cultures.

\begin{tabular}{|c|c|c|c|c|c|}
\hline Isolate & Age (months) & Sex & Clinical details & Stool & Coisolates \\
\hline 399.90 & 13 & Male & Mucoid diarrhoea & $\mathrm{L}$ & C.jj1 \\
\hline 191.91 & 30 & Female & Eosinophilia & $\mathrm{F}$ & None \\
\hline 199.91 & 1 & Female & Diarrhoea & $\mathrm{W}$ & C.upsal \\
\hline 249.92 & 9 & Female & Chronic diarrhoea & $\mathrm{W}$ & C.j doyl \\
\hline 327.92 & 48 & Female & Asthmatic & $\mathrm{F}$ & C.upsal \\
\hline 346.92 & 30 & Male & FTT & $\mathrm{F}$ & C.upsal \\
\hline 303.93 & 18 & Female & Asthma & $\mathrm{F}$ & C.upsal \\
\hline 307.93 & 12 & Female & Chronic diarrhoea & F & $\begin{array}{l}\text { C.j doyl, } \\
\text { C.upsal }\end{array}$ \\
\hline 321.93 & 24 & Female & Acute diarrhoea & $\mathrm{L}$ & C.upsal \\
\hline 355.93 & 31 & Male & Loose stools & $\mathrm{L}$ & None \\
\hline 388.93 & 7 & Male & Persistent diarrhoea & $\mathrm{W}$ & None \\
\hline 412.93 & 48 & Male & Chronic diarrhoea & $\mathrm{W}$ & C.upsal \\
\hline 78.94 & 14 & Female & Dysentery & $\mathrm{L}$ & C.jj1 \\
\hline 95.94 & 14 & Female & Chronic diarrhoea & $\mathrm{L}$ & C.conc \\
\hline 274.94 & 12 & Male & Chronic diarrhoea & $\mathrm{L}$ & C.j doyl \\
\hline 283.94 & 6 & Female & Chronic diarrhoea & $\mathrm{L}$ & None \\
\hline 296.94 & 7 & Female & Diarrhoea and vomiting & $\mathrm{W}$ & None \\
\hline 334.94 & $?$ & Female & $\begin{array}{c}\text { Blood culture } \\
\text { Pneumonia, septicaemia }\end{array}$ & & None \\
\hline 36.95 & 24 & Male & Periodic diarrhoea 2 months & $\mathrm{L}$ & Giardia \\
\hline 128.95 & 14 & Male & Prolonged diarrhoea & $\mathrm{L}$ & None \\
\hline 140.95 & 13 & Male & Dysentery & $\mathrm{F}$ & None \\
\hline 143.95 & 5 & Male & $\begin{array}{c}\text { Blood culture } \\
\text { diarrhoea, acidotic }\end{array}$ & & None \\
\hline 153.95 & 15 & Male & Kwashiorkor & $\mathrm{W}$ & C.upsal \\
\hline 400.95 & 30 & Female & Dysentery, chronic diarrhoea & $\mathrm{L}$ & C.upsal \\
\hline 366.96 & 31 & Male & Diarrhoea & $\mathrm{L}$ & None \\
\hline 384.96 & 12 & Female & Diarrhoea and vomiting & $\mathrm{L}$ & None \\
\hline 126.97 & 11 & Female & Gastroenteritis & $\mathrm{W}$ & None \\
\hline 137.97 & 18 & Male & HIV+ & $\mathrm{L}$ & C.upsal \\
\hline 155.97 & 13 & Male & $\begin{array}{c}\text { Blood culture } \\
\text { meningococcaemia }\end{array}$ & & None \\
\hline 178.97 & 12 & Female & Acute diarrhoea and vomiting & $\mathrm{L}$ & None \\
\hline 36.02 & 4 & Male & Umbilical haematoma & $\mathrm{L}$ & C.jj1 \\
\hline 37.02 & 6 & Female & $\begin{array}{l}\text { Blood culture } \\
\text { gastroenteritis, FTT marasmus, fever }\end{array}$ & & None \\
\hline 166.02 & 22 & Female & Gastroenteritis & $\mathrm{W}$ & C.upsal \\
\hline 237.02 & 8 & Female & $\begin{array}{c}\text { Blood culture } \\
\text { pneumonia }\end{array}$ & & None \\
\hline 58.05 & 5 & Male & Chronic diarrhoea & $\mathrm{L}$ & C.jj1 \\
\hline 7.06 & 11 & Female & Dysentery & $\mathrm{W}$ & None \\
\hline 1.07 & 33 & Female & Diarrhoea & $?$ & None \\
\hline 2.07 & 20 & Male & Dysentery & $?$ & None \\
\hline 3.07 & 15 & Male & Diarrhoea & $?$ & $\begin{array}{l}\text { C.conc } \\
\text { C.coli }\end{array}$ \\
\hline 1.08 & 22 & Male & Diarrhoea & $?$ & $\begin{array}{c}\text { Shigella } \\
\text { sonnei }\end{array}$ \\
\hline
\end{tabular}

Stools: L: loose, $\mathrm{W}=$ watery, $\mathrm{F}=$ formed, ?: not recorded. C. coli = Campylobacter coli, C.conc = Campylobacter concisus, C.jj1 = Campylobacter jejuni subsp. jejuni biotype 1, C.j doyl = Campylobacter jejuni subsp. doylei, C.upsal $=$ Campylobacter upsaliensis. FTT $=$ failure to hrive. 


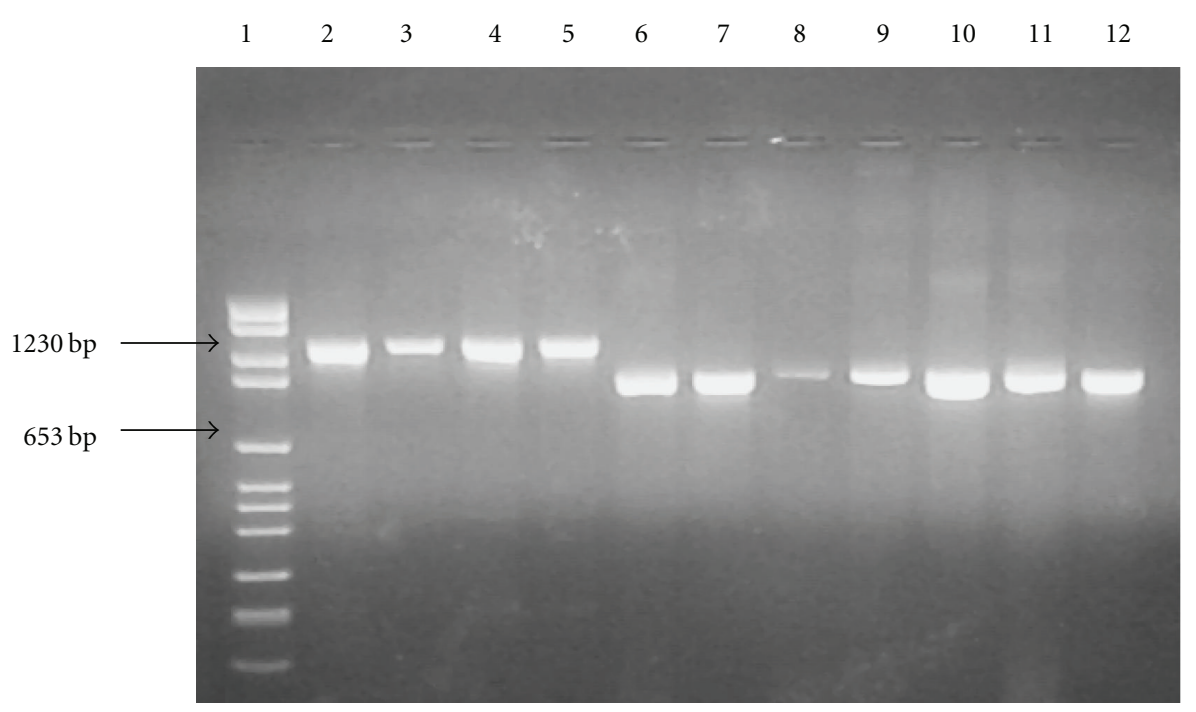

(a)

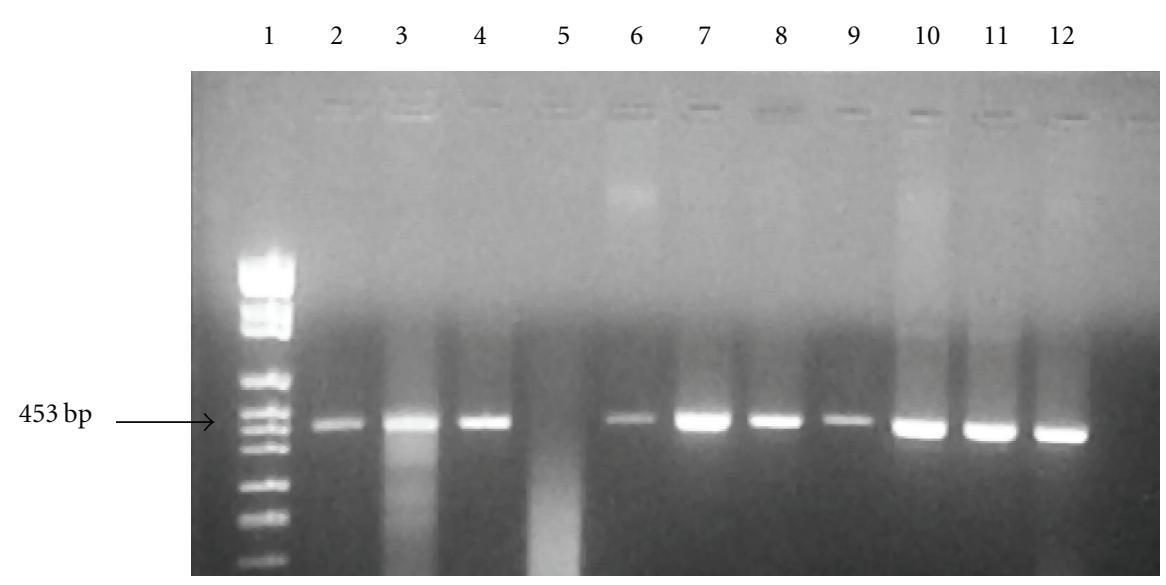

(b)

FIGURE 1: PCR amplicons of the (a) 16S rRNA gene of H. fennelliae (lanes 2-5) and other Helicobacter strains (lane 6: H. cinaedi, lanes 7-8: H. pylori, lane 9: H. mesocricetorum, lane 10: H. pametensis, lane 11: H. cholecystus, and lane 12: H. canadensis) and (b) rpoB gene of H. fennelliae (lanes 5-9) and other Helicobacter species (lane 2: H. pylori, lane 3: H. cinaedi, lane 4: H. canadensis, lane 10: H. pullorum, lane 11: H. mustelae, and lane 12: H. cholecystus).

but on a limited number of $H$. fennelliae samples $(n=13)$, where the larger fragment was successfully amplified, the separation of the South African isolates from the other strains is observed (Figure 2(b)). A single nucleotide change (C-T) at position 295 of the 16S rRNA differentiated the types of strains NCTC 11612, LMG 7546, and CCUG 18820 from the South African isolates. The 16S rRNA sequence of isolate 283.94, although clustered with the South African $H$. fennelliae isolates, had a region of $57 \mathrm{bp}$ (nt 10391096) with 10 nucleotide changes. BLAST analysis showed the sequence to have closest homology (97\%) with the $16 \mathrm{~S}$ rRNA of Campylobacter hyointestinalis subsp. lawsonii (accession number AB301965). H. fennelliae isolated from the blood did not cluster separately to those from stool samples (Figure 2(a)). The intraspecies variation of South African strains of $H$. fennelliae was $0.1-0.6 \%$ while between South African and the 3 type strains was $0.7-0.9 \%$.
3.4. Intervening Sequence. All $H$. fennelliae isolates contained an IVS of $355 \mathrm{bp}$. The DNA sequence was inserted at nucleotide position 175 (based on $H$. pylori type strain NCTC 11637, accession number Z25741). The IVS sequences were identical to the type strains NCTC 11612, LMG 7546, and CCUG 18820 with the exception of isolates 327-92, 24992, 355-93, 274-94, and 334-94. These 5 isolates had a C$\mathrm{T}$ transition at position 307 . The nucleotide composition of the region is A-T rich (64.5\%). BLAST analysis showed that $122 \mathrm{bp}$ of the IVS had a high similarity of $79 \%$ and $77 \%$ to the 23S rRNA of $H$. canis NCTC 12743 and Helicobacter sp. MIT 01-5592B, respectively, with an opposite polarity. In addition, there was a region of $70 \mathrm{bp}$ which showed significant homology (90\%) to H. mesocricetorum ATCC 700931. No open reading frames were noted.

The secondary structure of the 16S rRNA IVS predicted a conformation as seen in Figure 3(a) with free energies 


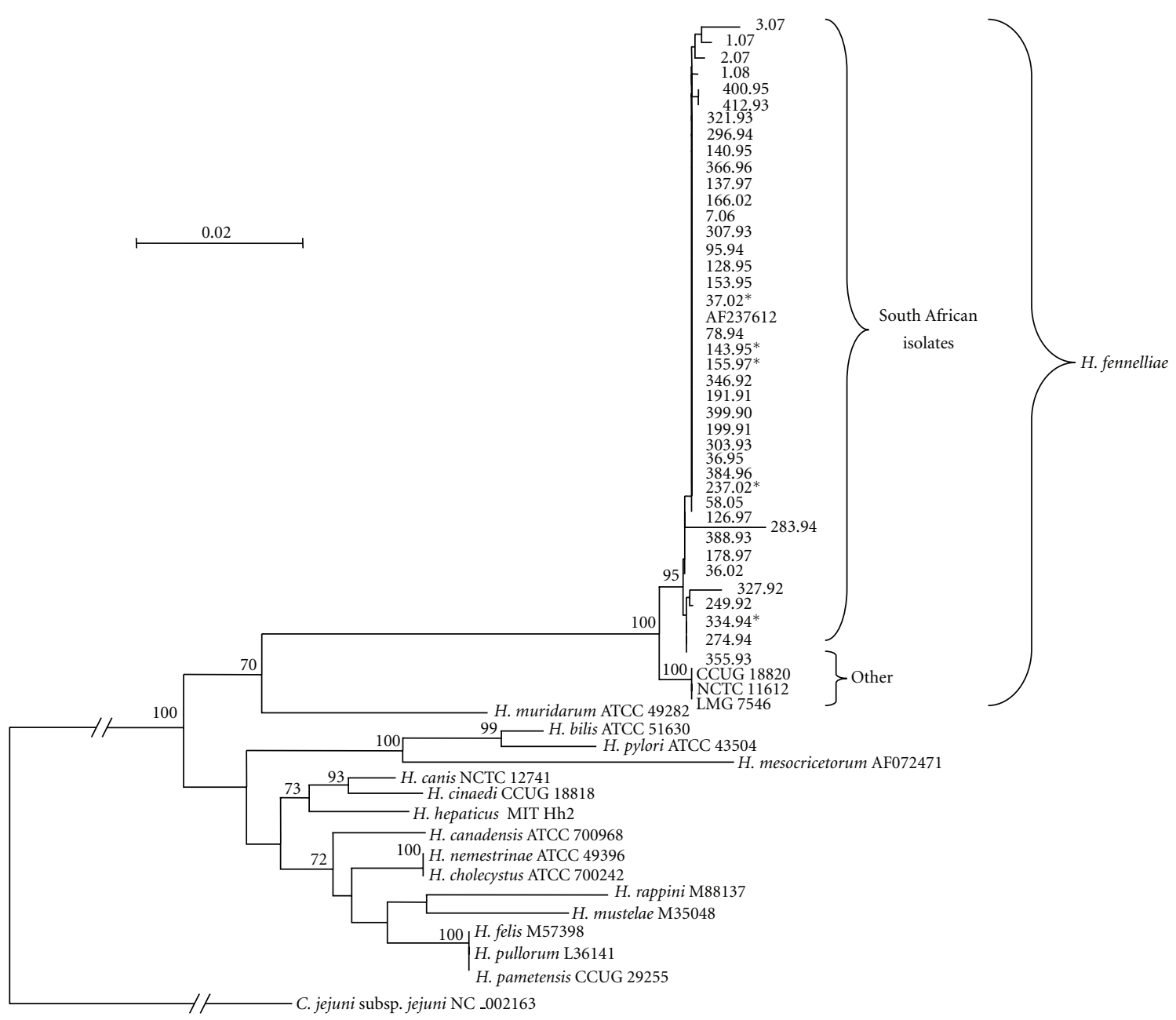

(a)

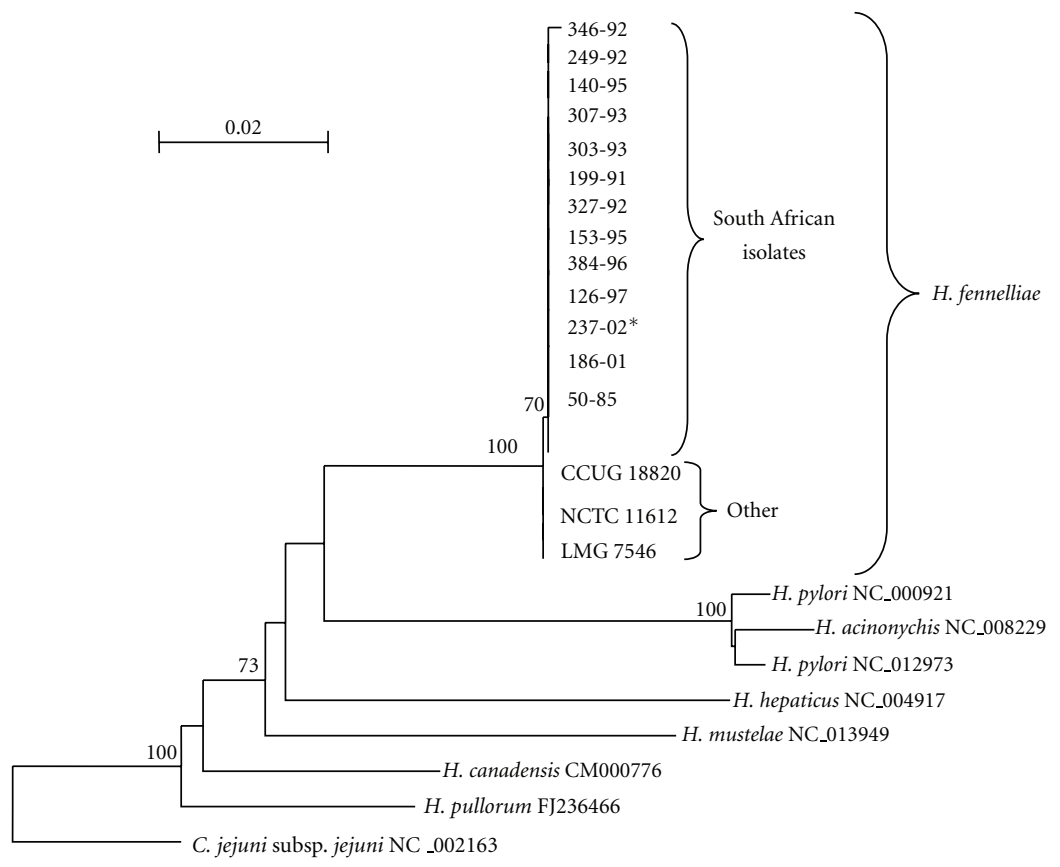

(b)

Figure 2: Phylogenetic trees of the $16 \mathrm{~S}$ rRNA (a) and rpoB gene (b) of H. fennelliae and other Helicobacter species. *indicates blood culture samples. 


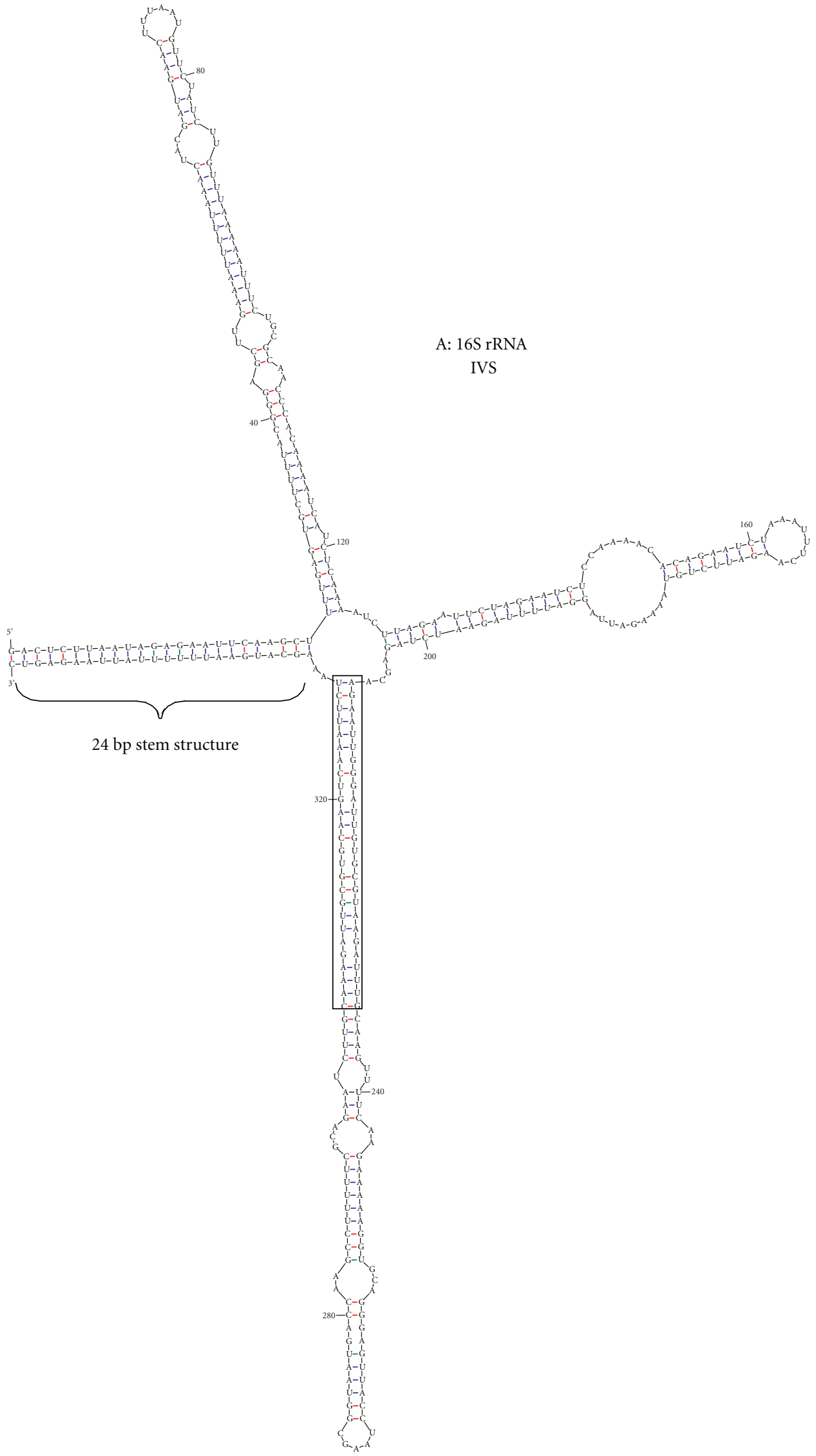

(a)

FIgURe 3: Continued. 


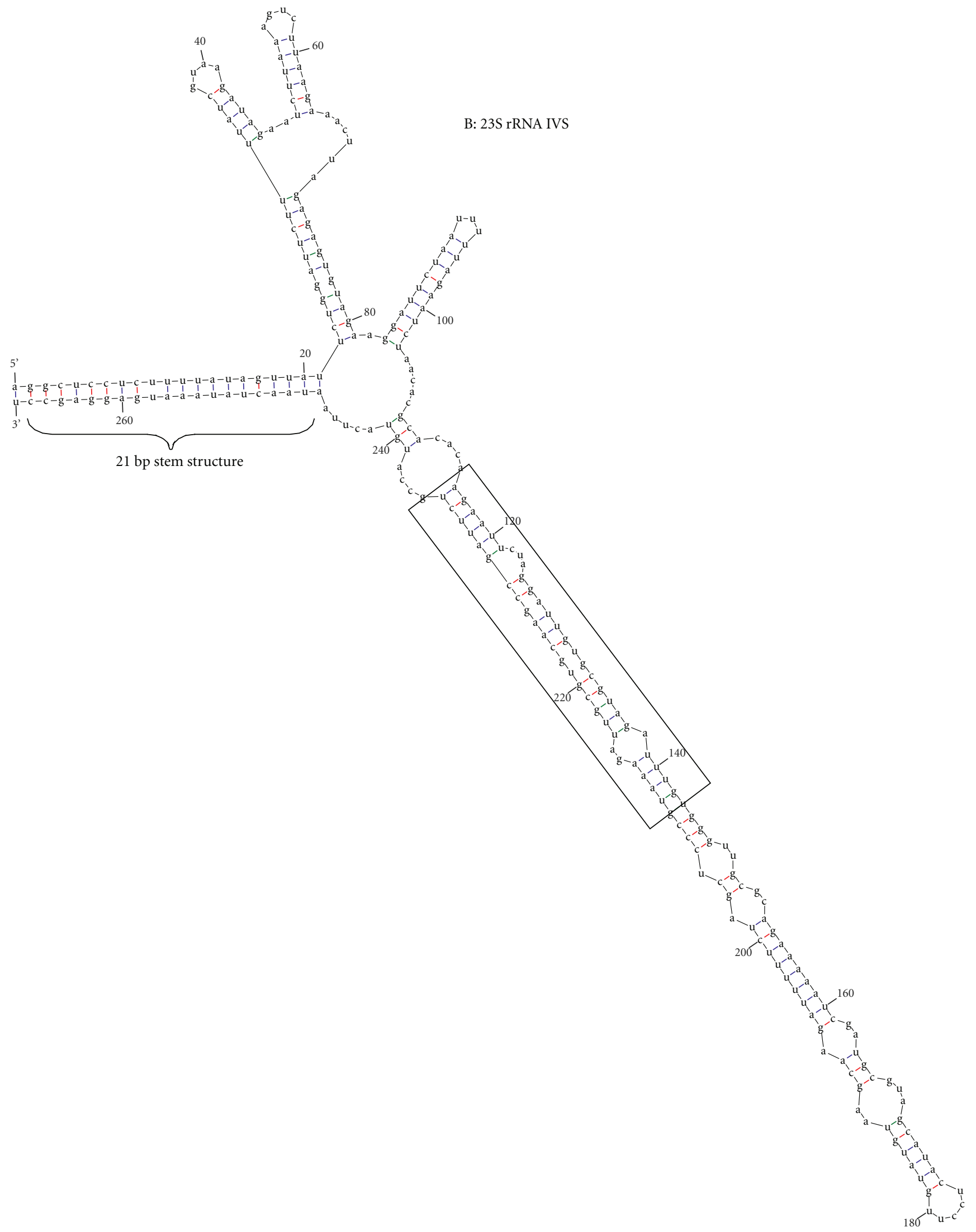

(b)

FIgURE 3: Predicted RNA secondary structures of the IVS from the $16 \mathrm{~S}$ rRNA (a) and 23S rRNA (b) of H. fennelliae. Boxed area shows region of homology between the 2 IVS sequences. 
of $-166.3 \mathrm{kcal} . \mathrm{mol}$ at $37^{\circ} \mathrm{C}$. No suboptimal structures were found. The $5^{\prime}$ and $3{ }^{\prime}$ ends of the $16 \mathrm{~S}$ rRNA IVS were complementary resulting in a $24 \mathrm{bp}$ stem structure. The 271 bp $23 S$ rRNA IVS of $H$. fennelliae CCUG 18820 had a similar $21 \mathrm{bp}$ stem structure (Figure 3(b)). A region of homology (26 bp) between the two IVS sequences was noted (boxed area Figure 3).

\section{Discussion}

This study identified 2 distinct genotypes of $H$. fennelliae based on the phylogenetic analysis of the 16S rRNA and rpoB genes. All isolates from South Africa clustered with the Helicobacter strain AF237612 isolated by Tee et al. [11], while the 3 isolates from the northern hemisphere, NCTC 11612, LMG 7546, and CCUG 18820, formed a separate branch with bootstrap value of $100 \%$. Tee et al. [11] proposed that their novel Helicobacter strain may be a new species based on the 16S rRNA sequence analysis and a sequence similarity of $\leq 97 \%$ with $H$. fennelliae CCUG 18820 (accession number M88154) [22]. Our analysis of the latter sequence does not support this observation. The discrepancy between these observations can possibly be explained by the fact that the original M88154 sequence, deposited in GenBank in 1993 by Dewhirst and Paster [23], was subsequently replaced in 2004 by the same authors. This is after the paper by Tee et al. was published in 2000. In the earlier M88154 sequence, no IVS was present. Our results suggest that Helicobacter strain AF237612 is probably a $H$. fennelliae species.

Sequencing of the housekeeping gene, rpoB, is increasingly being used to confirm $16 \mathrm{~S}$ rRNA-generated phylogenetic trees and identify bacteria and closely related species in the clinical setting [24]. The taxonomic resolution of this gene is more than 3 times greater than that of $16 \mathrm{~S}$ rRNA for a number of different bacteria, including Vibrio, Bacillis, and Pseudomonas [25-27]. In this study phylogenetic analysis of the larger rpoB fragment confirmed the separation of $H$. fennelliae isolates into 2 genotypes.

Intervening sequences of variable lengths and sequences can be found in both the small (16S rRNA) and large subunit ribosomal RNA (23S rRNA) of many bacteria [28]. These form stable stem-loop secondary structures [28]. IVSs have been described in a number of Campylobacter ( $C$. coli, $C$. curvus, C. fetus, C. helveticus, C. hyointestinalis, C. jejuni, C. sputorum, C. rectus, and C. upsaliensis, ) and Helicobacter $(H$. bilis, $H$. canis, $H$. fennelliae, $H$. mustelae, and $H$. muridarum) species [29-37]. The IVS found in the 16S rRNA of $H$. fennelliae isolates examined in this study is highly conserved. The A-T rich nature of this region is also preserved [28]. The $\mathrm{C}-\mathrm{T}$ transition noted in 5 isolates did not alter the secondary structure of the IVS (data not shown). Although the IVS of the $23 \mathrm{~S}$ rRNA is shorter than that of the 16S rRNA, there is a region of homology indicating a possible common ancestral element. The predicted secondary structures of both the $23 \mathrm{~S}$ rRNA and 16S rRNA contained a stem of $21 \mathrm{bp}$ and $24 \mathrm{bp}$ formed, respectively, by the 5 ' and 3 ' inverted repeats. These may act as recognition sites for excision by RNAse III during rRNA maturation $[28,34]$.
Most Helicobacter species that cause diarrhoea can also be isolated from the blood [6]. H. fennelliae is infrequently reported as causing bacteraemia, and this may in part be due to the fastidious nature of the organism $[11,36,38-40]$. In this study 5 of the $15 \mathrm{H}$. fennelliae strains isolated from the blood were examined. There were no sequence differences between $H$. fennelliae strains isolated from blood or stool samples.

In conclusion, this molecular and phylogenetic study is the largest undertaken of $H$. fennelliae with results indicating the presence of 2 genotypes. The South African isolates are more closely related to the Australian Helicobacter strain, a probable $H$. fennelliae species, isolated by Tee et al. [11] than to the 3 type strains.

\section{Acknowledgment}

This work was supported by an award (436194) from the Health Sciences Faculty Research Committee, University of Cape Town.

\section{References}

[1] J. R. Warren and B. J. Marshall, "Unidentified curved bacilli on gastric epithelium in active chronic gastritis," The Lancet, vol. 1, no. 8336, pp. 1273-1275, 1983.

[2] C. Seymour, R. G. Lewis, M. Kim et al., "Isolation of Helicobacter strains from wild bird and swine feces," Applied and Environmental Microbiology, vol. 60, no. 3, pp. 1025-1028, 1994.

[3] J. G. Fox, "The non-H pylori helicobacters: their expanding role in gastrointestinal and systemic diseases," Gut, vol. 50, no. 2, pp. 273-283, 2002.

[4] J. Stanley, D. Linton, A. P. Burnens et al., "Helicobacter pullorum sp. nov.-genotype and phenotype of a new species isolated from poultry and from human patients with gastroenteritis," Microbiology, vol. 140, no. 12, pp. 3441-3449, 1994.

[5] J. L. O'Rourke, A. Grehan, and M. Lee, "Non-pylori helicobacter species in humans," Gut, vol. 49, no. 5, pp. 601-606, 2001.

[6] J. V. Solnick, "Clinical significance of Helicobacter species other than Helicobacter pylori," Clinical Infectious Diseases, vol. 36, no. 3, pp. 349-354, 2003.

[7] K. Van Den Bulck, A. Decostere, M. Baele et al., "Identification of non-Helicobacter pylori spiral organisms in gastric samples from humans, dogs, and cats," Journal of Clinical Microbiology, vol. 43, no. 5, pp. 2256-2260, 2005.

[8] A. J. Lastovica and B. M. Allos, "Clinical significance of Campylobacter and related species other than Campylobacter jejuni and Campylobacter coli," in Campylobacter, I. Nachamkin, C. M. Szymanski, and M. J. Blaser, Eds., pp. 123149, ASM Press, Washington, DC, USA, 3rd edition, 2008.

[9] P. A. Totten, C. L. Fennell, F. C. Tenover et al., "Campylobacter cinaedi (sp. nov.) and Campylobacter fennelliae (sp. nov.): two new Campylobacter species associated with enteric disease in homosexual men," Journal of Infectious Diseases, vol. 151, no. 1, pp. 131-139, 1985.

[10] P. Vandamme, E. Galsen, R. Rossau et al., "Revision of Campylobacter, Helicobacter, and Wolinella taxonomy: emendation of generic descriptions and proposal of Arcobacter gen. nov," International Journal of Systematic Bacteriology, vol. 41, no. 1, pp. 88-103, 1991. 
[11] W. Tee, S. Hinds, J. Montgomery, and M. L. Dyall-Smith, "A probable new Helicobacter species isolated from a patient with bacteremia," Journal of Clinical Microbiology, vol. 38, no. 10, pp. 3846-3848, 2000.

[12] A. J. Lastovica, "Emerging Campylobacter spp.: the tip of the iceberg," Clinical Microbiology Newsletter, vol. 28, no. 7, pp. 49-56, 2006.

[13] K. Wilson, "Preparation of genomic DNA from bacteria," in Current Protocols in Molecular Biology, F. M. Ausubel, R. Brent, R. E. Kingston et al., Eds., supplement 24, pp. 2.4.1-2.4.5, John Wiley \& Sons, New York, NY, USA, 1990.

[14] S. M. Marshall, P. L. Melito, D. L. Woodward, W. M. Johnson, F. G. Rodgers, and M. R. Mulvey, "Rapid identification of Campylobacter, Arcobacter, and Helicobacter isolates by PCRrestriction fragment length polymorphism analysis of the $16 \mathrm{~S}$ rRNA gene," Journal of Clinical Microbiology, vol. 37, no. 12, pp. 4158-4160, 1999.

[15] C.-Y. Lim, K.-H. Lee, M.-J. Cho et al., "Detection of Helicobacter pylori in gastric mucosa of patients with gastroduodenal diseases by PCR-restriction analysis using the RNA polymerase gene (rpoB)," Journal of Clinical Microbiology, vol. 41, no. 7, pp. 3387-3391, 2003.

[16] P. Kuhnert, A. P. Burnens, S. L. W. On, and P. A. R. Vandamme, "Misidentifying Helicobacter cinaedi," Journal of Clinical Microbiology, vol. 39, no. 7, pp. 2751-2752, 2001.

[17] J. D. Thompson, T. J. Gibson, F. Plewniak, F. Jeanmougin, and D. G. Higgins, “The CLUSTAL X windows interface: flexible strategies for multiple sequence alignment aided by quality analysis tools," Nucleic Acids Research, vol. 25, no. 24, pp. 4876-4882, 1997.

[18] Y. Van de Peer and R. De Wachter, "TREECON for Windows: a software package for the construction and drawing of evolutionary trees for the Microsoft Windows environment," Computer Applications in the Biosciences, vol. 10, no. 5, pp. 569-570, 1994.

[19] D. H. Mathews, J. Sabina, M. Zuker, and D. H. Turner, "Expanded sequence dependence of thermodynamic parameters improves prediction of RNA secondary structure," Journal of Molecular Biology, vol. 288, no. 5, pp. 911-940, 1999.

[20] M. Zuker, "Mfold web server for nucleic acid folding and hybridization prediction," Nucleic Acids Research, vol. 31, no. 13, pp. 3406-3415, 2003.

[21] F. E. Dewhirst, Z. Shen, M. S. Scimeca et al., "Discordant 16 S and 23S rRNA gene phylogenies for the genus Helicobacter: implications for phylogenetic inference and systematics," Journal of Bacteriology, vol. 187, no. 17, pp. 6106-6118, 2005.

[22] E. Stackebrandt and B. M. Goebel, "A place for DNA-DNA re-association and 16S rRNA sequence analysis in the present species definition in bacteriology," International Journal of Systematic and Evolutionary Microbiology, vol. 44, pp. 846849, 1994.

[23] F. E. Dewhirst and B. J. Paster, "Helicobacter fennelliae (CCUG 18820) partial 16S ribosomal RNA," 1993, http://www.ncbi.nlm.nih.gov/nuccore/174807.

[24] T. Adékambi, M. Drancourt, and D. Raoult, "The rpoB gene as a tool for clinical microbiologists," Trends in Microbiology, vol. 17, no. 1, pp. 37-45, 2009.

[25] L. Ait Tayeb, E. Ageron, F. Grimont, and P. A. D. Grimont, "Molecular phylogeny of the genus Pseudomonas based on $r p o B$ sequences and application for the identification of isolates," Research in Microbiology, vol. 156, no. 5-6, pp. 763 $773,2005$.
[26] J.-S. Ki, W. Zhang, and P.-Y. Qian, "Discovery of marine Bacillus species by $16 \mathrm{~S}$ rRNA and rpoB comparisons and their usefulness for species identification," Journal of Microbiological Methods, vol. 77, no. 1, pp. 48-57, 2009.

[27] J.-S. Ki, R. Zhang, W. Zhang, Y.-L. Huang, and P.-Y. Qian, "Analysis of RNA polymerase beta subunit (rpoB) gene sequences for the discriminative power of marine vibrio species," Microbial Ecology, vol. 58, pp. 679-691, 2009.

[28] E. Evguenieva-Hackenberg, "Bacterial ribosomal RNA in pieces," Molecular Microbiology, vol. 57, no. 2, pp. 318-325, 2005.

[29] M. E. Konkel, R. T. Marconi, D. J. Mead, and W. Cieplak Jr., "Identification and characterization of an intervening sequence within the $23 \mathrm{~S}$ ribosomal RNA genes of Campylobacter jejuni," Molecular Microbiology, vol. 14, no. 2, pp. 235-241, 1994.

[30] D. Linton, J. P. Clewley, A. Burnens, R. J. Owen, and J. Stanley, "An intervening sequence (IVS) in the 16S rRNA gene of the eubacterium Helicobacter canis," Nucleic Acids Research, vol. 22, no. 11, pp. 1954-1958, 1994.

[31] D. Linton, F. E. Dewhirst, J. P. Clewley, R. J. Owen, A. P. Burnens, and J. Stanley, "Two types of 16S rRNA gene are found in Campylobacter helveticus: analysis, applications and characterization of the intervening sequence found in some strains," Microbiology, vol. 140, no. 4, pp. 847-855, 1994.

[32] T. J. Trust, S. M. Logan, C. E. Gustafson et al., "Phylogenetic and molecular characterization of a $23 \mathrm{~S}$ rRNA gene positions the genus Campylobacter in the epsilon subdivision of the Proteobacteria and shows that the presence of transcribed spacers is common in Campylobacter spp," Journal of Bacteriology, vol. 176, no. 15, pp. 4597-4609, 1994.

[33] J. G. Fox, L. L. Yan, F. E. Dewhirst et al., "Helicobacter bilis sp. nov., a novel Helicobacter species isolated from bile, livers, and intestines of aged, inbred mice," Journal of Clinical Microbiology, vol. 33, no. 2, pp. 445-454, 1995.

[34] A. Hurtado, J. P. Clewley, D. Linton, R. J. Owena, and J. Stanley, "Sequence similarities between large subunit ribosomal RNA gene intervening sequences from different Helicobacter species," Gene, vol. 194, no. 1, pp. 69-75, 1997.

[35] Y. Etoh, A. Yamamoto, and N. Goto, "Intervening sequences in 16s rRNA genes of Campylobacter sp.: diversity of nucleotide sequences and uniformity of location," Microbiology and Immunology, vol. 42, no. 3, pp. 241-243, 1998.

[36] C. S. Harrington and S. L. W. On, "Extensive 16S rRNA gene sequence diversity in Campylobacter hyointestinalis strains: taxonomic and applied implications," International Journal of Systematic Bacteriology, vol. 49, no. 3, pp. 1171-1175, 1999.

[37] C. A. Kemper, P. Mickelsen, A. Morton, B. Walton, and S. C. Deresinski, "Helicobacter (Campylobacter) fennelliae-like organisms as an important but occult cause of bacteraemia in a patient with AIDS," Journal of Infection, vol. 26, no. 1, pp. 97-101, 1993.

[38] V. L. Ng, W. K. Hadley, and C. Fennell, "Successive bacteremias with "Campylobacter cinaedi" and "Campylobacter fennelliae" in a bisexual male," Journal of Clinical Microbiology, vol. 25, no. 10, pp. 2008-2009, 1987.

[39] S. L. Orlicek, D. F. Welch, and T. L. Kuhls, "Helicobacter fennelliae bacteremia in a child with leukemia," Infectious Diseases in Clinical Practice, vol. 3, no. 6, pp. 450-451, 1994.

[40] P.-R. Hsueh, L.-J. Teng, C.-C. Hung et al., "Septic shock due to Helicobacter fennelliae in a non-human immunodeficiency virus-infected heterosexual patient," Journal of Clinical Microbiology, vol. 37, no. 6, pp. 2084-2086, 1999. 


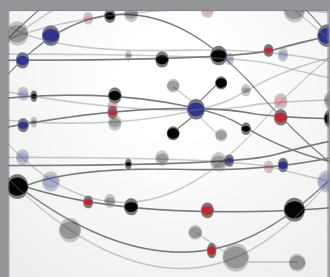

The Scientific World Journal
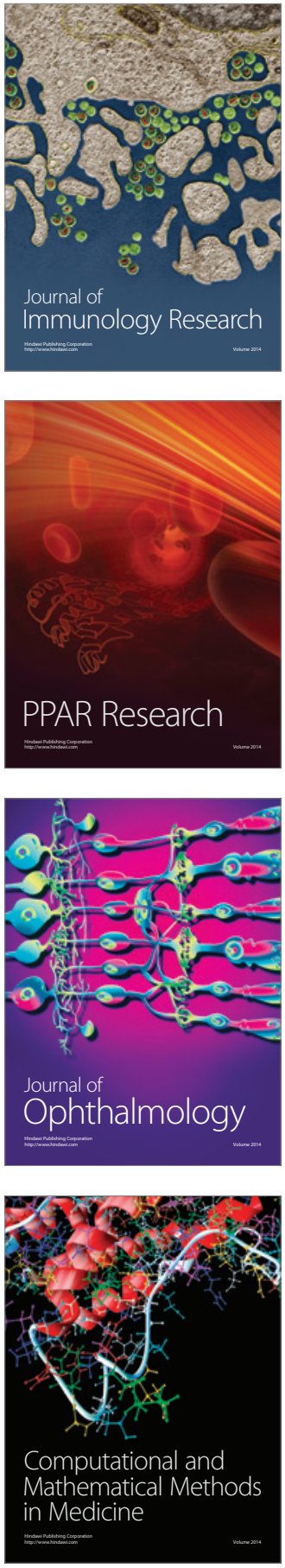

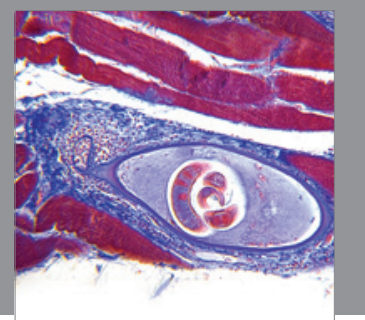

Gastroenterology

Research and Practice
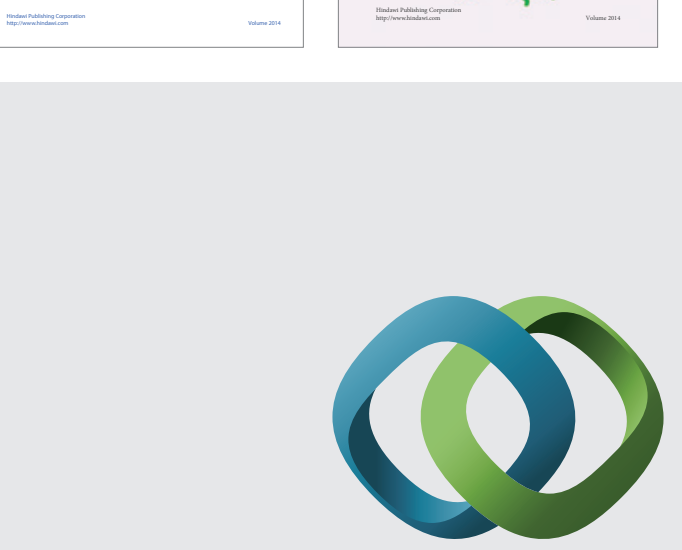

\section{Hindawi}

Submit your manuscripts at

http://www.hindawi.com
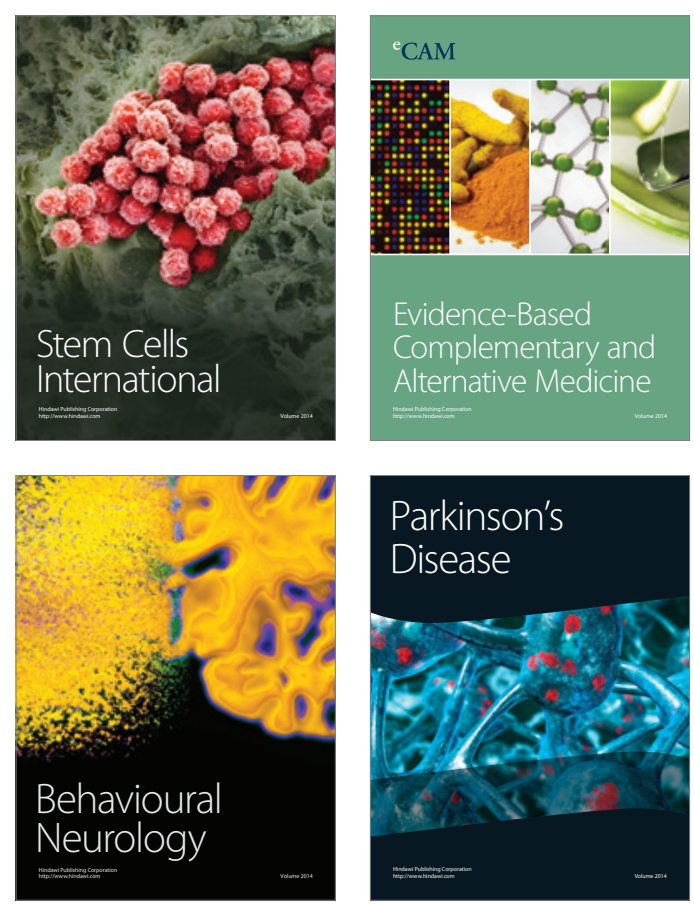

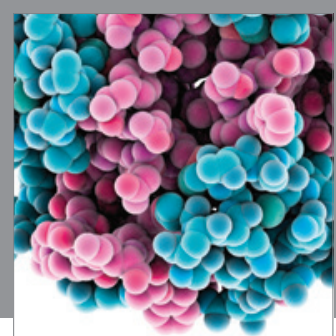

Journal of
Diabetes Research

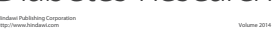

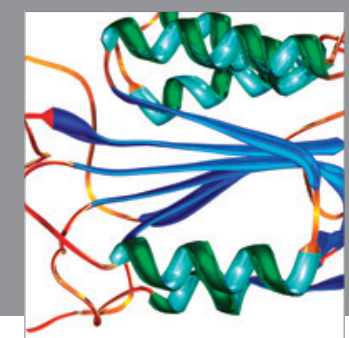

Disease Markers
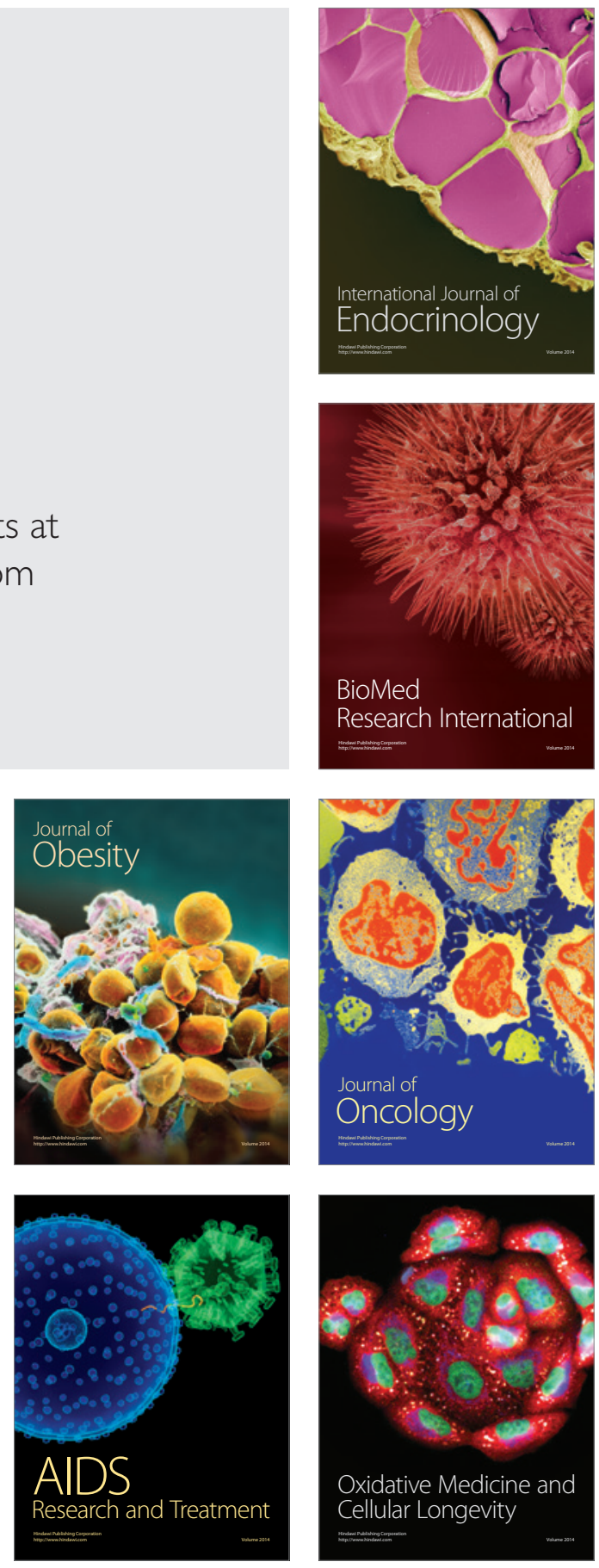